\title{
A FURTHER STUDY OF THE PROBLEM OF THE MAINTENANCE OF FEMALES IN GYNODIOECIOUS SPECIES
}

\author{
D. CHARLESWORTH \\ School of Biological Sciences, University of Sussex, Falmer, Brighton BN1 9QG
}

Received 17.vi.80

\section{SUMMARY}

\begin{abstract}
Models for the maintenance of females in gynodioecious species are reviewed. Some new results are given concerning digenic models and models of cytoplasmic inheritance with restorer genes, when the cytoplasmic and nuclear factors may have fitness effects in addition to their effects on male fertility. It is suggested that many gynodioecious species may be interpreted as having a cytoplasmic-genic inheritance of male-sterility, and that this interpretation would resolve a number of difficulties. However, much of the evidence is circumstantial, and complete details of the genetics are not available for any case of natural polymorphism for male-sterility. This makes it impossible to test the population genetics theories in a more precise way. It is clear, however, that both the digenic and the cytoplasmic-genic model require large fitness differences if a polymorphism for females is to be maintained. Some evidence exists in maize for the type of fitness effect required by the cytoplasmic-genic model.
\end{abstract}

\section{INTRODUCTION}

Despite having been studied for a considerable time, the problem of how females are maintained in gynodioecious species remains unsolved (for a review, see Ross, 1978). Until the genetic basis for male-sterlity is known, it seems unlikely that we will understand how this type of polymorphism is maintained. The earliest studies of such species suggested that cytoplasmic inheritance was often involved (e.g., Correns, 1906; 1908; 1916). From the first, however, complications have been noted. Female plants in most gynodioecious species can produce hermaphrodite progeny, and the progeny of hermaphrodites can be female (Correns, 1906; 1908). Furthermore, "intermediate" forms are known in several gynodioecious species. These are usually hermaphrodites with some female flowers (e.g., Correns, 1906; 1916; Kheyr-Pour, 1975; Ross, 1969). Also, the expression of male-sterility may sometimes be affected by environmental conditions. Finally, even the females are sometimes variable, showing different degrees or different types of male-sterility (e.g., Plantago lanceolata, Van Damme, personal communication). In summary, it is clear that none of the twelve species that has been thoroughly studied has simple single-factor nuclear or cytoplasmic control of male-sterility.

Two possible modes of inheritance involving two factors have been considered likely. One model that could account for the findings mentioned above, is cytoplasmic inheritance together with restorer genes. This model would reconcile the clear evidence for cytoplasmic influence that exists for some species (e.g., Origanum vulgare, Kheyr-Pour, 1975; Chenopodium quinoa, Simmonds, 1971; Nemophila menziesii, Ganders, 1978) with some of the complications mentioned above. Cytoplasmic-genic inheritance of 
this sort is well known in several cultivated species (e.g., maize, Duvick, 1965). In some cases environmental influences on the expression of malesterility, and intermediate forms, have been noted (Duvick, 1965), providing a parallel with the observations on naturally occurring malesterility. However, a number of genetic studies of gynodioecious species have yielded data suggesting two-locus nuclear control of male-sterility (O. vulgare, Lewis and Crowe, 1956; P. lanceolata, Ross, 1969; Cortaderia richardii, Connor, 1973).

The purpose of the present paper is to review the conditions for maintenance of females in populations, assuming various modes of inheritance, in particular two factor models, and to integrate the conclusions about fitness differences required for the maintenance of this kind of polymorphism, with data about fitness effects associated with male-sterility factors. Unfortunately, few data on fitness effects associated with male sterility are available at present. Differences in seed output between females and hermaphrodites have been demonstrated in several species, in natural conditions (Darwin, 1877; Connor, 1973). However, such differences must be determined in a complex fashion by the ovule outputs of the two phenotypes together with their chances of pollination. Only in self-incompatible species can we take such data as direct estimates of the fitness effects of the male-sterility factors. Such data exist for the selfincompatible species, Hirschfeldia incana (Horovitz and Beiles, 1980) and Plantago lanceolata (unpublished work of van Damme). Detailed estimates of fitness parameters require an understanding of the genetic system involved. Some information exists for maize (Duvick, 1965). This rather fragmentary information is insufficient to allow us to decide unequivocally between alternative genetic models for gynodioecy, but a model-building approach, using the information we have and generating testable predictions, should help advance our understanding. Clearly, no model can be accepted unless it permits a polymorphism for females to exist, and unless the necessary fitness effects can be demonstrated in the species in question.

\section{Models AND RESUltS}

(i) Cytoplasmic-genic models

The cytoplasmic-genic model studied is related to the models of simple nuclear inheritance of femaleness studied by Lewis (1941), Lloyd (1974, 1975) and by Charlesworth and Charlesworth (1978); Lewis (1941) and Lloyd (1974) also studied simple cytoplasmic inheritance. Previous studies of cytoplasmic-genic inheritance either assumed no fitness differences (Watson and Caspari, 1960; Caspari et al., 1966; Costantino, 1971), or only those associated with inbreeding depression and differential seed output of the two phenotypes, females and hermaphrodites (Charlesworth and Ganders, 1979). None of these models permits joint equilibria.

The model studied here generalises the model of Charlesworth and Ganders (1979) to allow for the possibility of fitness differences associated with either the cytoplasmic or the nuclear factor, or both, as proposed by Delannay (1979). Table 1 summarises the model. It is expressed as a cytoplasmic-genic model, but obviously covers, as a special case, simple nuclear genic inheritance with a recessive male-sterility gene $m$ (when $\mathbf{S}$ 
TABLE 1

Model of cytoplasmic male-sterility with a dominant nuclear restorer and effects of both cytoplasmic and nuclear factors on female fertility

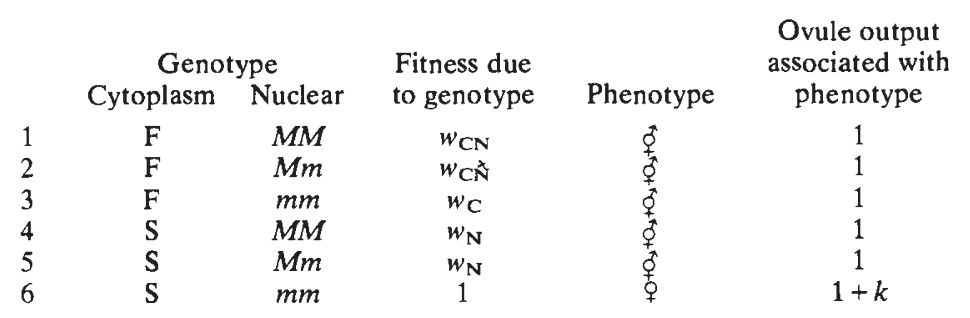

cytoplasm is fixed); when $m$ is fixed, we have cytoplasmic inheritance. The fitness effects are all assumed to act on female fertilities. The effect of the restorer $(M)$ gene is assumed to be dominant, and its restorer action is also assumed dominant, and sporophytically controlled. Cases of gametophytic action are known, for example in maize (Duvick, 1965). The fitness effect of the $M$ gene in S cytoplasm is $w_{\mathrm{N}}$, and the fitness effect of $\mathrm{F}$ (non-malesterile) cytoplasm in the $\mathrm{mm}$ genotype is $w_{\mathrm{C}}$. Femaleness is assumed to increase ovule output by a proportion $k$, compared with that of hermaphrodites. Other parameters used in the model are the selfing rate, $s$, of hermaphrodites, the inbreeding depression, $\delta$, defined as the relative lowering of viability of a product of self-compared with cross-fertilisation, and $x$ the number of pollinator visits (see Lloyd, 1974); the chance that a nonselfed ovule does not get pollinated, due to the pollinator having previously visited only females, decreases as $x$ increases. The recurrence equations for this model are given in the Appendix.

Figure 1 summarises the conditions for the spread of nuclear or cytoplasmic male-sterility factors with the simple fitness model of table 1 , assuming large $x$ (i.e., all non-selfed ovules assumed to be fertilised). Note that neither $\delta$ nor the fertility of females is constant. The spread of females in the population is likely to affect the amount of inbreeding depression, but this has not been taken into account in any models of gynodioecy. Also, the relative fertility of females declines as their frequency rises (see Lloyd, 1974). The fertility of females, relative to that of hermaphrodites, when females are present in frequency $z$, will be written as $1+k_{z}$. Equation (A.1) in the Appendix gives the expression for $k_{z}$, for the case of a dominant restorer, assuming that inbreeding depression acts to cause mortality after seeds are produced. (If selfed ovules are subject to very early mortality, the seed output of hermaphrodites would be lower than the value used in equation (A.1), and the value of $k_{z}$ correspondingly greater.) The conditions for spread of rare male-sterility factors obviously involve $k$, the value for the situation when no females are present; these conditions are shown in fig. 1. When $s=0$, the chance of pollination of non-selfed ovules does not enter into the recurrence equations, since females and hermaphrodites are affected identically. For completely outcrossing species, the relative fertility of females is therefore the same for all frequencies of females, and can be measured directly. When there is some selfing, we can measure $k_{z}$, but even if the other fitness parameters are known we cannot estimate $k$ without detailed information about the chances of pollination. 


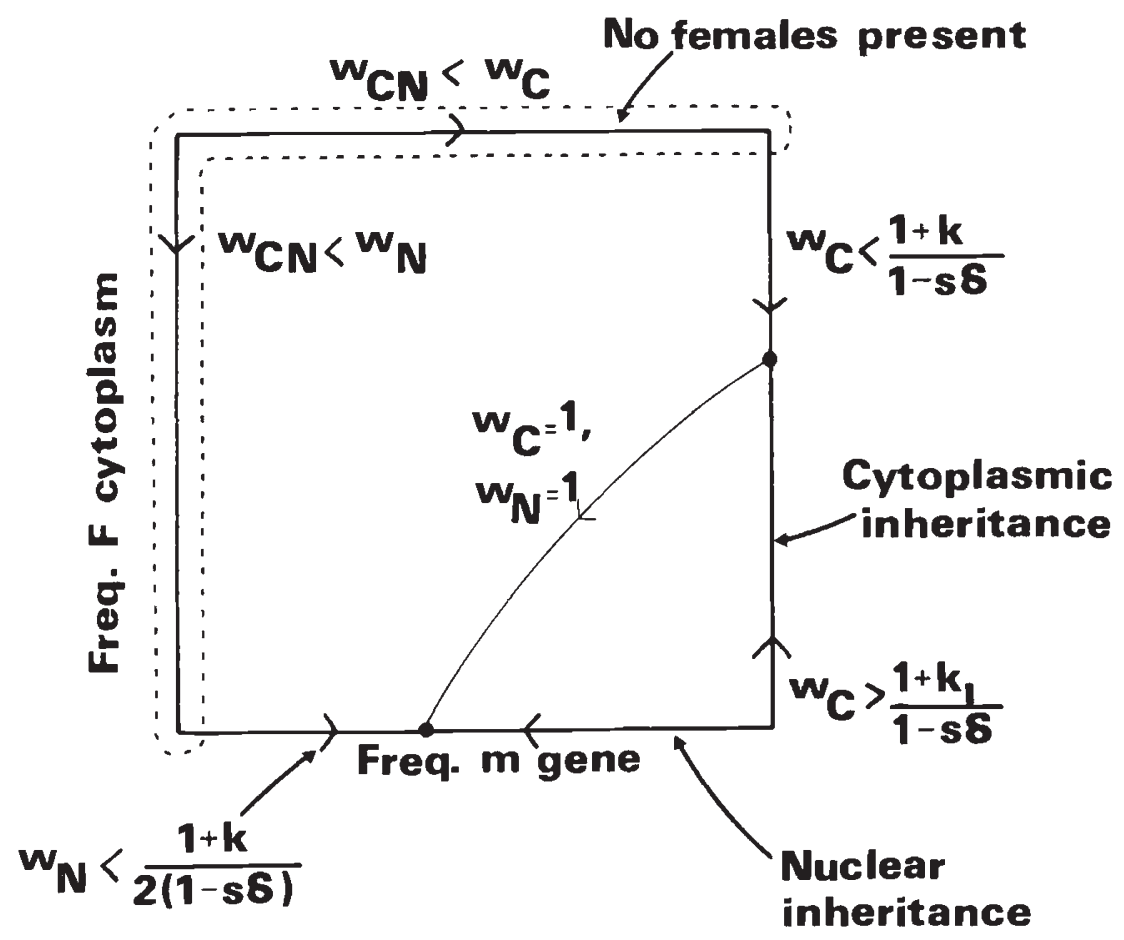

FIG 1.-Conditions for the maintenance of females in populations with nuclear or cytoplasmic male-sterility factors having effects on female fertility.

If there is no selfing, the lack of dependence of $k_{z}$ on the frequency of females means that the condition for an $\mathrm{S}$ cytoplasm to spread is also the condition for its fixation. We would therefore not expect to find cytoplasmic male-sterility maintained stably in a self-incompatible species. For a nuclear male-sterility factor, the condition for spread (Charlesworth and Charlesworth, 1978) is also the condition for a polymorphic equilibrium to exist (Lloyd, 1974). Figure 1 also indicates that when the F cytoplasm or the $M$ gene is fixed, so that there are no females, the other factor cannot be maintained polymorphic, but will be fixed or lost depending purely on its own fitness effect. The case of $w_{N}=w_{C}=1$ is equivalent to the model of Charlesworth and Ganders (1979); fig. 1 indicates that in this case the introduction of a restorer gene into a population polymorphic for a cytoplasmic male-sterility factor leads to the elimination of the F cytoplasm so that the final population is either fixed for the restorer in S cytoplasm, or remains polymorphic for the restorer. Cytoplasmic inheritance thus changes over to nuclear inheritance of male-sterility.

Delannay et al. (1980) showed that with the model of table 1 joint cytoplasmic-genic equilibria can exist. Of the many possible models of this type, these authors studied the case of a dominant, sporophytically-acting restorer gene with all fitness effects acting on female fertility, and with the effects of the cytoplasmic and nuclear genotypes combining multiplicatively (so that $w_{\mathrm{CN}}$ in table 1 would be the product of $w_{\mathrm{C}}$ and $w_{\mathrm{N}}$ ). As can be seen in the Appendix, the recurrence relations for this type of model are complex, 
and yield little insight into the behaviour to be expected in the interior of graphs like fig. 1, unless simplifying assumptions, such as 100 per cent selfing, are made (Delannay et al., 1980), and even then the system remains quite complex. It therefore seems best to use a computer to calculate the recurrence relations. Three types of starting populations appear plausible; equilibrium for a cytoplasmic factor; equilibrium for a male-sterility gene; or in cases where neither equilibrium exists, the restorer mutation might arise while the $S$ cytoplasm is spreading to fixation in an $\mathrm{mm}$ population.

Table 2 and fig. 2 show details of some of the results, assuming the model of Delannay et al. (1980). Four cases are shown illustrating the four possibilities with respect to the existence of the boundary equilibria ( $(a)$ only the genic equilibrium exists; $(b)$ only cytoplasmic equilibrium; (c) no boundary equilibrium; $(d)$ both boundary equilibria exist. Parameter values for these runs are given in table 2 . Detailed studies of the conditions for the existence of a joint equilibrium have been performed by Delannay et al. (1980), and I have also run many sets of parameter values, assuming the same model and some variants (see below).

TABLE 2

Parameter values for the runs shown in Figure 2, and details of the equilibria reached

\begin{tabular}{|c|c|c|c|c|c|}
\hline & \multicolumn{3}{|c|}{ Run } & \multirow[b]{2}{*}{ (d) } \\
\hline & & (a) & (b) & (c) & \\
\hline & \multicolumn{5}{|c|}{ Parameter values } \\
\hline$s$ & & 0 & 0.7 & 0.99 & $0 \cdot 7$ \\
\hline$\delta$ & & 0 & $0 \cdot 1$ & 0 & $0 \cdot 7$ \\
\hline$x$ & & - & 1 & $10^{7}$ & 1 \\
\hline$w_{\mathrm{C}}$ & & $1 \cdot 1$ & 1 & 1 & $1 \cdot 2$ \\
\hline$w_{N}$ & & $0 \cdot 6$ & $0 \cdot 8$ & $0 \cdot 8$ & 1 \\
\hline \multirow[t]{2}{*}{$1+k$} & & $1 \cdot 25$ & $1 \cdot 25$ & $1 \cdot 25$ & $1 \cdot 25$ \\
\hline & \multicolumn{5}{|c|}{ Equilibrium results } \\
\hline \multicolumn{2}{|l|}{ Frequency of females } & $0 \cdot 14$ & $0 \cdot 19$ & $0 \cdot 24$ & 0.05 \\
\hline \multicolumn{2}{|l|}{$\begin{array}{l}\text { Relative seed output } \\
\text { of females, compared } \\
\text { with } \oint_{\uparrow}^{\hat{m} \text { mean }}\end{array}$} & $1 \cdot 88$ & $1 \cdot 20$ & $1 \cdot 36$ & $1 \cdot 06$ \\
\hline \multicolumn{6}{|l|}{$\begin{array}{l}\text { Frequency of crosses } \\
\text { giving different } \\
\text { frequencies of females }\end{array}$} \\
\hline \multirow[t]{3}{*}{$q \times \phi$} & 0 & $0 \cdot 316$ & $0 \cdot 192$ & $0 \cdot 202$ & 0.559 \\
\hline & $\frac{1}{2}$ & 0.599 & 0.310 & $0 \cdot 206$ & 0.357 \\
\hline & 1 & 0.086 & 0.499 & 0.591 & $0 \cdot 083$ \\
\hline \multirow{3}{*}{ 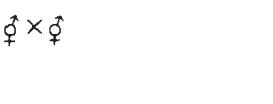 } & 0 & 0.739 & 0.835 & 0.837 & 0.929 \\
\hline & & 0.228 & 0.063 & $0 \cdot 042$ & 0.058 \\
\hline & $\frac{1}{2}$ & 0.033 & $0 \cdot 102$ & $0 \cdot 120$ & $0 \cdot 014$ \\
\hline
\end{tabular}

Figure 2 illustrates the fact that joint equilibrium is possible in all four situations with respect to the existence of the boundary equilibria, with various amounts of selfing including $s=0$, and can occur with $x$ ranging from 1 to very high values. Although strong fitness effects are usually necessary for joint equilibrium (and also for equilibrium for nuclear genes), such equilibria are also possible when the cytoplasmic factor or (rarely) when the 

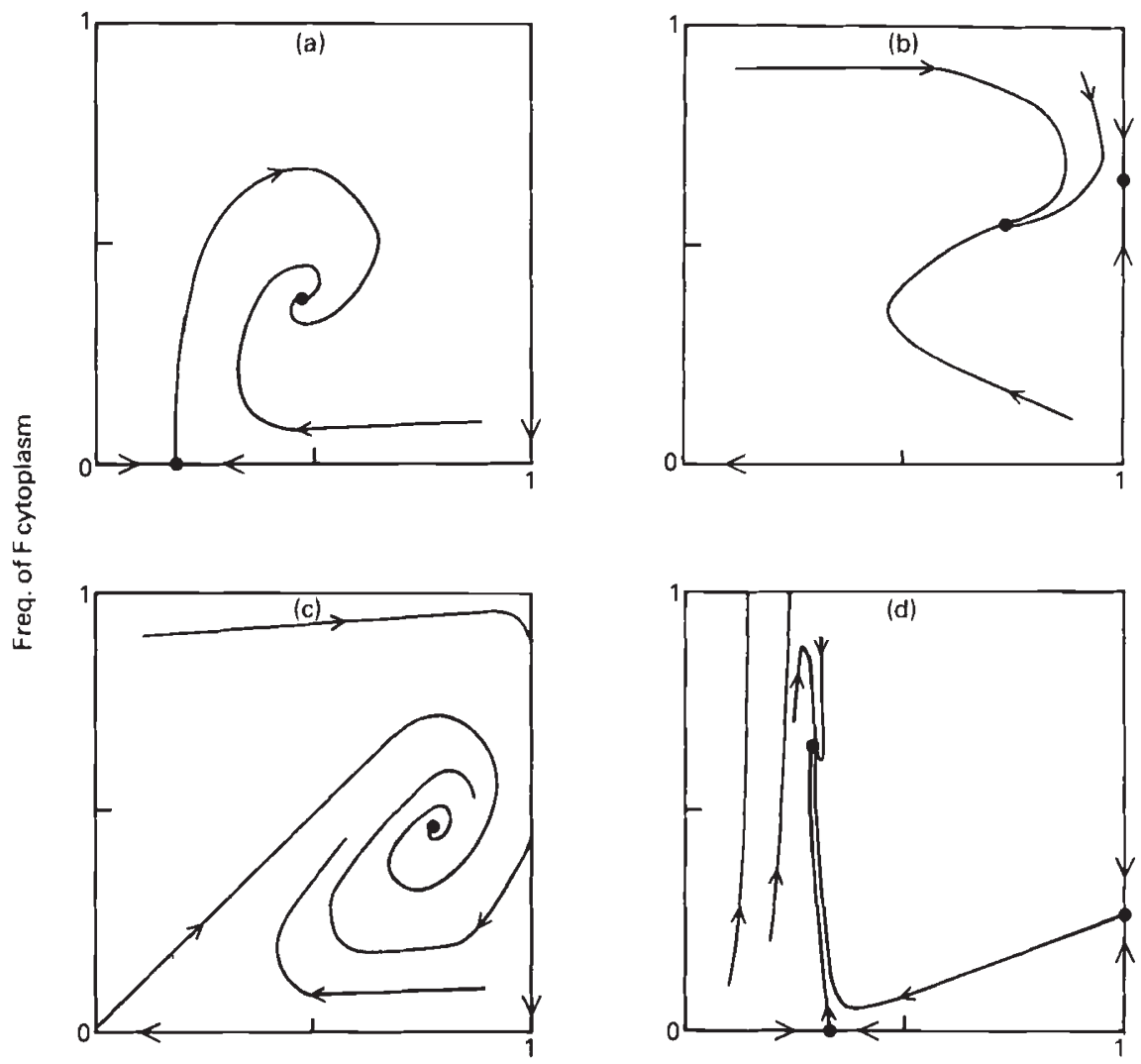

Frequency of $m$ Gene

FIG. 2.-Trajectories of population change for populations with nuclear and cytoplasmic sterility factors. Parameter values (shown in table 1) permitting existence of joint equilibria are illustrated.

$M$ gene has no effect. It is helpful to consider separately the effects of the fitness factors $w_{C}$ and $w_{N}$.

From the results of numerous runs, it appears that $w_{N}>1$ does not permit joint equilibrium; when $s=1, w_{\mathrm{N}}<1$ is necessary. No case of joint polymorphism with $w_{\mathrm{N}}>1$ has been found, with any value of $w_{\mathrm{C}}, s$ or $\delta$. With $w_{N}=1$, the outcome of the run often depends on the initial state; with low frequencies of $m$ the F cytoplasm is fixed, whereas if the $m$ gene was common enough, the system moved to a position on a line of very slow change, with final fixation or loss of $F$ cytoplasm, depending on the parameter values. In one case (shown in fig. $2 \mathrm{~d}$ ), the changes were so slow that it appeared that a joint equilibrium had been found. With $w_{\mathrm{N}}$ slightly greater than 1, but the other parameter values as in the case of the run shown in fig. $2 \mathrm{~d}$, there was no such equilibrium.

With the less plausible assumption that $w_{C}=1$, joint equilibria are readily found, though if $s=0, w_{C}>1$ is necessary. When $s>0, w_{C}$ can even be less than 1 , for some values of the other parameters. 
Table 2 shows details of the equilibria illustrated in fig. 2. The low frequencies of females at equilibrium are typical of this type of system, though Gouyon (personal communication) has found a parameter set yielding 57 per cent females. Very high frequencies of females, such as have been found in Thymus vulgaris (Pigott, 1955), Silene vulgaris (Marsden-Jones and Turrill, 1957; own unpublished data), and occasionally in $P$. lanceolata (Baker, 1963), seem unlikely to be produced with this type of model, though they can occur if viability differences exist between genotypes (see below). At equilibrium, the seed output of females relative to the average for the various hermaphrodite genotupes (i.e., $1+k_{z}$, as given by equation (A.1) in the Appendix) depends in a complex way on the parameter values. High values can be obtained when there are large differences in the values of the fertility parameters, though the values at equilibrium are of ten considerably below those that would be anticipated from the $w$ and $k$ values alone. The segregation ratios (table A1) that would be obtained from such equilibrium populations are also shown. Different parameter sets yield very different properties in this respect, but it is rare to find that a great proportion of females will produce all female progenies, at equilibrium. Generally, all three types of progenies of females, and of hermaphrodites, would be found so that the results from such equilibrium populations would resemble those obtained from actual gynodioecious species (e.g., Correns, 1908).

It is easy to modify the recurrence relations to model viability effects on fitness (i.e., $w_{\mathrm{C}}$ and $w_{\mathrm{N}}$ being viabilities instead of ovule outputs), or recessive restorer action. Viability selection would be plausible for species for which no, or small, differences in seed output between females and hermaphrodites exist (though as will be discussed below, nearly all the species for which data are available show a considerably raised seed production in females). Both these models yield conclusions similar to those described above. With viability selection, the equilibrium frequencies of females were higher than those in table 2 , for the same parameter values. Of course, many other forms of these models could be studied. For example, a dominant restorer gene might have a recessive action on fitness, rather than dominant action as assumed above. Alternatively, a recessive restorer might nevertheless affect fitness in the heterozygote. No case of joint equilibrium has been found in this case, though they may be possible. One might also remove the assumption of multiplicative interactions. However, in the absence of estimates of any of the assumed effects, in any species, detailed studies of these variants do not seem worthwhile. It is perhaps of interest, however, to point out that most parameter values give oscillations in the gene and cytoplasm frequencies (see fig. 2), and that the same population could therefore appear very different at different times. Also, equilibrium is sometimes reached very slowly. It would therefore be unwise to assume that any observed population is in equilibrium.

\section{(ii) Two locus models}

This type of model was proposed by Lewis and Crowe (1956) to account for their findings in Origanum vulgare. Two alleles at each of two loci are assumed $(F, f$ and $H, h) . F$ can be regarded as a dominant male-sterility gene, which is suppressed by $H$; alternatively $h$ is a recessive male-sterility gene, which is not expressed in $f f$. In order to account for the ratios in some 
of the families ffhh was assumed to be inviable, and other genotypes also had to have strong viability differences. Thus, this type of model also potentially involves a large number of parameters. Two approaches have been tried, out of the many possible ones.

One approach, due to Ross and Shaw (1971), assumes no fitness effects other than an increase, $k$, in the fecundity of females, compared with hermaphrodites. These authors found by computer calculation that, for any given female fecundity, the proportion of females in the equilibrium population was the same as for a one-locus model; this was true for two other models of the interaction between the loci, in addition to the one described above. It is easy to prove that this must be the case, even with some degree of selfing $(s)$ and inbreeding depression $(\delta)$, provided that no other fitness effects exist. Consider a locus that forms part of a two (or more) locus system causing male-sterility of some genotypes, with complete dominance at all loci such that only two phenotypes, hermaphrodite and female, exist in the system. The equation for change in frequency at such a locus is given by equation (3) of Charlesworth and Charlesworth (1978). This shows that equilibrium requires that the fitness of the females and hermaphrodites be the same; the condition applies to each locus in the system. It follows that, at equilibrium for a two-locus system, the phenotype frequencies will be the same as with the single-locus system, since the fitnesses depend only on the fixed $k, s$ and $\delta$ values and on the phenotype frequencies. This result means that if a population is at equilibrium for one male-sterility locus, a new allele at another locus such as the second locus in any of the systems studied by Ross and Shaw (1971) would not invade, as the population would already be at the phenotypic equilibrium state. This makes this simple type of twolocus model unlikely as an explanation for the findings in gynodioecious species.

If, however, we impose the additional assumption that ffh is lethal, there are no longer just two phenotypes in terms of fitness, and it is necessary to do computer calculations. The result of such runs is that $f$ is eliminated. It therefore appears that if this type of model operates in Origanum vulgare, there must indeed be other fitness differences associated with the different genotypes.

The second approach to study of the two-locus models is to assume fitnesses as estimated by Lewis and Crowe (1956). This has been done by Jain (1968), who showed that two-locus polymorphisms can be maintained, but that this requires very strong selection (viability of $H H$ less than $0 \cdot 5$, and of ffhh less than $0 \cdot 25$ ).

\section{Discussion}

The results of studying the models described above do not lead to any marked clarification of the genetic situation in any species, since both the two factor systems studied can be maintained in populations, given strong enough selection. The digenic models seem somewhat implausible, particularly as near lethality of the ffh $h$ genotype seems to be required for maintenance of $h$ (Jain, 1968) and this has not been found in the other species for which this system has been proposed, Cordateria richardii (Connor, 1973). Furthermore, Origanum vulgare, for which the digenic model was originally suggested by Lewis and Crowe (1956) has been studied 
by Kheyr-Pour (1975) and re-interpreted as a case of cytoplasmic inheritance with restorer genes. The genetic ratios that one would obtain in crosses under these two models, are rather similar; female frequencies in progenies of females could be $\frac{3}{8}, \frac{1}{2}$ or 1 on the digenic model and $\frac{1}{2}, \frac{3}{4}$ or 1 on a cytoplasmic model with a recessive restorer, while progenies of hermaphrodites could have female frequencies ranging from $0-1$ on either model, though ratios of $\frac{1}{8}, \frac{3}{16}$ and $\frac{1}{4}$ occur only on the digenic model. The two models may thus be hard to distinguish, purely on the basis of family data, especially when there are viability differences.

The cytoplasmic-genic type of model seems more likely to apply in gynodioecious species, though there may be cases of simple cytoplasmic inheritance (e.g., Cirsium oleraceum, Correns, 1916). Hirschfeldia incana at first appeared to be another case, but restorer genes are probably present at low frequency (Horovitz and Galil, 1972) and this is also likely for Satureia hortensis (Correns, 1908). The clearest cases of cytoplasmic-genic systems are Thymus vulgaris (Valdeyron et al., 1977) and Nemophila menziesii (Ganders, 1978), but the details of the restoration by nuclear factors are not entirely clear. Although Origanum vulgare has cytoplasmic iheritance of male-sterility in some crosses, and restorer genes are also present (KheyrPour, 1975), matters are complicated by the existence of more than one sterility cytoplasm; it is not clear that any local population contains more than one cytoplasm, or that male-sterility within populations is ever inherited cytoplasmically. Thus, even in the best studied species with genic-cytoplasmic systems many uncertainties remain.

The situation in other species is even less certain. Cirsium palustre may be a case of cytoplasmic-genic inheritance; much of the data (Correns, 1916) fits nuclear genic male-sterility, but irregularities exist that suggest cytoplasmic factors. Limnanthes douglasii has been reported to have a dominant male-sterility gene (Baker, 1966; Jain et al., 1978). Females of this species, when crossed with hermaphrodites, give either 50 per cent or 100 per cent female progeny. But if male-sterility is dominant, homozygous females cannot arise (unless there is also a ge notype which carries the factor but in which the sterility is suppressed). It is therefore impossible for this species to have as simple a mode of inheritance as has been proposed, and it seems likely that there is a cytoplasmic factor also. No clear conclusions can be reached about Silene vulgaris (Correns, 1906; Marsden-Jones and Turrill, 1957) or Centaurea scabiosa (Fröst, 1963), though joint inheritance could well be the case for either of these. In Plantago lanceolata clear evidence exists for both nuclear factors (Ross, 1969) and cytoplasmic differences (Ross, 1967; van Damme, personal communication).

If cytoplasmic-genic inheritance is indeed the system in any of these species, the computer calculations show that quite large fitness differences are to be expected between females and hermaphrodites, and between different hermaphrodite genotypes. It would be interesting to know whether these do in fact exist. Unfortunately, the only fitness data that have been obtained are measures of seed production by females and hermaphrodites in the natural state. It is often found that seed production of females exceeds that of hermaphrodites (Darwin, 1877; Connor, 1973), but one cannot be sure that this is not due to the progeny of hermaphrodites being partly produced by selfing, with seed failure due to inbreeding depression. In $H$. incana, which is self-incompatible, however, this cannot be the 
explanation, and here similar results have been obtained (Horovitz and Beiles, 1980). Van Damme (personal communication) also finds this in $P$. lanceolata, another self-incompatible species (Correns, 1908; Ross, 1973). An interesting conclusion from the computer results is that joint equilibria are possible with $s=0$. This confirms the suggestion of Horovitz and Beiles (1980) that the findings in $H$. incana could be due to the presence of restorer genes; this species thus appears not to be a contradiction of the prediction that cytoplasmic male-sterility cannot exist in a self-incompatible species. If there are restorer genes present, it is misleading to refer to the system as "cytoplasmic" inheritance.

In maize, fitness estimates for the different genotypes, even under one set of environmental conditions, only exist for one of the three male-sterility cytoplasms (Texas), and for one restorer gene $\left(R f_{1}\right)$. No fitness effect of $R f_{1}$ could be detected. Duvick (1965) reviews evidence that Texas cytoplasm reduces seed output (by 2 per cent in normal corn belt conditions) whereas male-sterility increases it by about the same amount, so that in cultivation the yield of Texas male-steriles is approximately equal to that of non-malesterile cytoplasm lines. Chinwuba et al. (1961) have evidence for an increase in seed output in maize associated with the female phenotype, apart from that due to the presence of male-sterility factors; in crowded conditions $k$ values as large as 0.26 were found, when male-sterility was due to detasselling. Fitnesses such as these could not maintain a joint cytoplasmicgenic equilibrium (see above). Indeed, a quite specific type of fitness effect is required in order to maintain a joint equilibrium, restorer genes associated with lowered fitness (see section 2(i) above). The only data of which I am aware, other than that quoted above, indicate that newly arisen restorer mutations in maize are associated with a syndrome of deleterious effects that would reduce fitness (Laughnan and Gabay, 1978). More data on the fitness effects of male-sterility factors in both cultivated species, and in naturally occurring male sterility, would be very valuable. If restorer mutations with deleterious effects arise, a mechanism would exist for converting cytoplasmic inheritance of male-sterility into cytoplasmic-genic inheritance. This could explain the otherwise surprising fact that there are so few cases of simple single-factor inheritance of male sterility. The model of Charlesworth and Ganders (1979), in which the restorer genes have no fitness effects, predicts that the spread of restorers will convert cytoplasmic into nuclear inheritance, but none of the well-studied species has this mode of inheritance. It could be argued that cytoplasmic factors with associated fitness effects, such as were assumed in section 2(i) above of ten arise and convert nuclear male-sterility systems into joint systems. There is, however, little evidence for cytoplasmic mutations; the male-sterility cytoplasms in maize generally appear highly stable (Duvick, 1965), although loss of the sterility property occurs in some strains of maize (Laughnan and Gabay, 1978), usually due to reversion from sterile to non-male-sterile cytoplasm.

Another possible reason for the rarity of populations with nuclear genic control of male-sterility is that they may evolve towards dioecy. Ross (1978) has argued that this is very likely to occur, as the kinds of mutations required reducing the female fertility of the hermaphrodites are a common occurrence. This process has also been studied by Charlesworth and Charlesworth (1978) who showed that evolution from recessive genically controlled gynodioecy to dioecy most likely depends on the 
occurrence of linked modifiers reducing female fertility, so the process might not be as fast as the occurrence of female sterility mutations in general would suggest. Alternatively, mutations that affect female fertility in the hermaphrodites, but not the females, could be involved. Certainly the occurrence of dioecy, apparently newly evolved, in the floras of oceanic islands, seems to support the view that dioecy can readily evolve (Baker, 1967).

Acknowledgements. - I wish to thank Drs Delannay, Gouyon and Valdeyron for sending me their unpublished papers, and for helpful correspondence, and J. van Damme for discussions and for making available his unpublished data.

\section{REFERENCES}

BAKER, H. G. 1963. Evolutionary mechanisms in pollination biology. Science, 139, 877-883. BAKER, H. G. 1966. The evolution of floral heteromorphism and gynodioecism in Silene maritima. Heredity, 21, 689-692.

BAKER, H. G. 1967. Support for Baker's law-as a rule. Evolution, 21, 853-856.

CASPARI, E., WATSON, G. S., AND SMITH, w. 1966. The influence of cytoplasmic pollen sterility on gene exchange between populations. Genetics, 53, 741-746.

CHARLESWORTH, B., AND CHARLESWORTH, D. 1978. A model for the evolution of dioecy and gynodioecy. Amer. Nat., 112, 975-997.

CHARLESWORTH, D., AND GANDERS, F. R. 1979. The population genetics of gynodioecy with cytoplasmic-genic male-sterility. Heredity, 43, 213-218.

CHINWUBA, P. M., GROGAN, C. O., AND ZUBER, M. s. 1961. Interaction of detasseling, sterility and spacing on maize yields. Crop Sci., 1, 179-280.

CONNOR, H. E. 1973. Breeding systems in Cortaderia (Graminae). Evol., 27, 663-678.

CORRENS, C. 1906. Die Vererbung der Geschlechtsformen bei den Gynodiöcischen Pflanzen. Ber. deutsche Bot. Ges., 24, 459-474.

CORRENS, C. 1908. Die Rolle der männlichen Keimzellen bei der Geschlechtsbestimmung der gynodiöecischen Pflanzen. Ber deutsch Bot. Ges. 26A, 686-701.

CORRENS, C. 1916. Untersuchungen über Geschlechtsbestimmung bei Distelarten. Sitz. Kgl. Preuss. Akad. Wiss., 447-477.

COSTANTINO, R. F. 1971. Genetic consequences of the couplet cytoplasmic pollen sterility and pollen migration. Genetics, 71, 313-321.

DARWIN, C. 1877. Different forms of flowers on plants of the same species. John Murray, London.

DELANNAY, X. 1979. Etude cytologique et mathématique de l'évolution des mécanismes de reproduction dans le genre Cirsium Miller. Thesis, University of Louvain.

DELANNAY, X., GOUYON, P. H., AND VALDEYRON, G. 1980. Mathematical study of the evolution of gynodioecy with cytoplasmic inheritance under the effect of a nuclear restorer gene. (In press).

DUVICK, D. N. 1965. Cytoplasmic pollen sterility in corn. Adv. Genet., 13, 1-56.

FRÖST, S. 1963. Cytoplasmic pollen sterility in Centaurea scabiosa. Hereditas, 49, 454-456.

GANDERS, F. R. 1978. The genetics and evolution of gynodioecy in Nemophila menziesii (Hydrophyllaceae). Can. J. Bot., 56, 1400-1408.

HOROVITZ, A., AND GALIL, J, 1972. Gynodieocism in East Mediterranean Hirschfeldia incana Cruciferae. Bot. Gaz., 133, 127-131.

HOROVITZ, A., AND BEILES, A. 1980. Gynodioecy as a populational strategy for increasing reproductive output. Theor. Appl. Genet., 57,11-15.

JAIN, S. K. 1968. Gynodioecy in Origanum vulgare: computer simulation of a model. Nature $217,764-765$.

JAIN, S. K., BOUSSY, I. A. AND HAUPTLI, M. 1978. Male sterility in meadowfoam. J. Hered., 69, 61-63.

KHEYR-POUR, A. 1975. Determinisme généntique et répartition écologique de la sterilité mâle cytoplasmique chez Origanum vulgare $L$. Thesis, Univ. des Sciences et Techniques de Languedoc, Montpellier.

LAUGHNAN, J. R., AND GABAY, S. J. 1978. Nuclear and cytoplasmic mutations to fertility in $S$ male-sterile maize. In Maize breeding and genetics, ed. D. B. Walden. Wiley, New York.

LEWIS, D. 1941. Male-sterility in natural populations of hermaphrodite plants. New Phytol., $40,56-63$. 
LEWIS, D., AND CROWE, L. K. 1956. The genetics and evolution of gynodioecy. Evol., 10, $115-125$.

LLOYD, D. G, 1974. Theoretical sex ratios of dioecious and gynodioecious angiosperms. Heredity, 32, 11-31.

LLOYD, D. G. 1975. The maintenance of gynodioecy and androdioecy in angiosperms. Genetics, 45, 325-339.

MARSDEN-JONES, E. M., AND TURRILL, w. B. 1957. The Bladder Campions. Ray Society, London.

PIGOTT, C. D. 1955. Thymus L. J. Ecol, 43, 365-387.

ROSS, M. D. 1967. Two genetic mechanisms governing outbreeding in Plantago lanceolata. Genetics, 56, 584-585. (Abstract).

Ross, M. D. 1969. Digenic inheritance of male sterility in Plantago lanceolata. Can. J. Genet., $11,739-744$.

ROSS, M. D. 1973. Inheritance of self-incompatibility in Plantago lanceolata. Heredity, 30, 169-176.

ROSS, M. D. 1978. The evolution of gynodioecy and subdioecy. Evolution, 32, 174-188.

ROSS, M. D., AND SHAW, R. F. 1971. Maintenance of male sterility in plant populations. Heredity, 26, 1-8.

simmONDS, N. W. 1971. The breeding system of Chenopodium quinoa. I. Male-sterility. Heredity, 27, 73-82.

VALDEYRON, G., DOMMÉE, B., AND VERNET, P. 1977. Self-fertilization in male-fertile plants of a gynodioecious species: Thymus vulgaris L. Heredity, 39, 243-249.

WATSON, G. S., AND CASPARI, E. 1960. The behaviour of cytoplasmic pollen sterility in populations. Evolution, 14, 56-63.

\section{APPENDIX}

Recurrence equations for cytoplasmic male-sterility with a restorer gene present. The restorer is assumed to be dominant and sporophytic in action, and the fitness contributions of the gene and the cytoplasmic factor are assumed to act on female fertility. The genotypes are numbered as in table 1 in the text, and their frequencies after selection (i.e., inbreeding depression) has acted, are denoted by $g_{i}$. The frequency of females is $z\left(=g_{6}\right)$, and the frequency of pollen bearing the $M$ allele is $p$. If the ovule output of genotype $i$ is $w_{i}$, then in order to calculate the contributions to the next generation, we must work in terms of $h_{i}=g_{i} w_{i}$. The other parameters are defined in the text; $t=1-s$.

$$
\begin{aligned}
& W g_{1}^{\prime}=\left(h_{1}+\frac{h_{2}}{4}\right) s(1-\delta)+t\left(1-z^{x}\right)\left(h_{1}+\frac{h_{2}}{2}\right) p \\
& W g_{2}^{\prime}=\frac{h_{2}}{2} s(1-\delta)+t\left(1-z^{x}\right)\left[h_{1}(1-p)+\frac{h_{2}}{2}+h_{3} p\right] \\
& W g_{3}^{\prime}=\left(\frac{h_{2}}{4}+h_{3}\right) s(1-\delta)+t\left(1-z^{x}\right)\left(\frac{h_{2}}{2}+h_{3}\right)(1-p) \\
& W g_{4}^{\prime}=\left(h_{4}+\frac{h_{5}}{4}\right) s(1-\delta)+t\left(1-z^{x}\right)\left(h_{4}+\frac{h_{5}}{2}\right) p \\
& W g_{5}^{\prime}=\frac{h_{5}}{2} s(1-\delta)+t\left(1-z^{x}\right)\left[h_{4}(1-p)+\frac{h_{5}}{2}\right]+\left(1-z^{x}\right)(1+k) g_{6} p \\
& W g_{6}^{\prime}=\frac{h_{5}}{4} s(1-\delta)+\left(1-z^{x}\right)(1-p)\left[t \frac{h_{5}}{2}+g_{6}(1+k)\right] \\
& z=g_{6}
\end{aligned}
$$




$$
\begin{aligned}
p & =\frac{g_{1}+g_{4}+\frac{1}{2}\left(g_{2}+g_{5}\right)}{1-g_{6}} \\
W & =\left(h_{1}+h_{2}+h_{3}+h_{4}+h_{5}\right)\left[s(1-\delta)+t\left(1-z^{x}\right)\right]+g_{6}(1+k)\left(1-z^{x}\right) .
\end{aligned}
$$

At any stage, the relative seed set of females, compared with hermaphrodites can be calculated, assuming that inbreeding depression does not affect the production of seed, but merely lowers subsequent survival of inbred seed. We have

$$
1+k_{z}=(1+k)\left(1-z^{x}\right)(1-z) /\left(h_{1}+h_{2}+h_{3}+h_{4}+h_{5}\right)\left[s+t\left(1-z^{x}\right)\right] \text {. }
$$

It is also easy to calculate the proportion of $+\times \phi^{+}$crosses (between individual plants) that will yield each of the possible ratios of females in the progeny. Table A1 shows the formulae for these, and for progenies of pairs of hermaphrodites crossed together.

\section{TABLE A1}

Frequencies of different types of families that would be expected

Type of cross

$$
q \times \$
$$

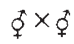

$$
\begin{aligned}
& 0 \\
& \frac{1}{4} \\
& \frac{1}{2}
\end{aligned}
$$

Frequency of $\phi$ individuals that give this ratio

$$
\begin{gathered}
\left(g_{1}+g_{4}\right) /(1-z) \\
\left(g_{2}+g_{5}\right) /(1-z) \\
g_{3} /(1-z)
\end{gathered}
$$

Freq. of crosses that give this ratio

$$
\overbrace{\left[\begin{array}{c}
\left.g_{1}+g_{2}+g_{3}+g_{4}+\frac{g_{5}\left(g_{1}+g_{4}\right)}{1-z}\right] /(1-z) \\
g_{5}\left(g_{2}+g_{5}\right) /(1-z)^{2} \\
g_{5} g_{3} /(1-z)^{2}
\end{array}\right.}
$$

The equations for a recessive restorer are as follows. The equations giving $g_{1}^{\prime}, g_{2}^{\prime}, g_{3}^{\prime}$ are exactly as above.

$$
\begin{aligned}
W g_{4}^{\prime} & =h_{4} s(1-\delta)+t\left(1-z^{x}\right) h_{4} p+\frac{h_{5}}{2}(1+k)\left(1-z^{x}\right) p \\
W g_{5}^{\prime} & =t\left(1-z^{x}\right) h_{4}(1-p)+\left(1-z^{x}\right)(1+k)\left(\frac{h_{5}}{2}+h_{6} p\right) \\
W g_{6}^{\prime} & =\left(1-z^{x}\right)(1+k)(1-p)\left(\frac{h_{5}}{2}+h_{6}\right) \\
z & =g_{5}+g_{6} \\
p & =\frac{g_{1}+g_{4}+\frac{1}{2} g_{2}}{1-g_{5}-g_{6}} \\
W & =\left(h_{1}+h_{2}+h_{3}+h_{4}\right)\left[s(1-\delta)+t\left(1-z^{x}\right)\right]+\left(g_{5}+g_{6}\right)(1+k)\left(1-z^{x}\right) .
\end{aligned}
$$

The relative seed set of females is given by the same expression as above (A.1) except that only genotypes 1 to 4 are hermaphrodites, in the present case. The modification for the case when the restorer has a fitness effect in heterozygotes is obvious. Quantities like those in table A1 are also easy to calculate. 